Kazeem O. Aremu, Chinedu Izuchukwu, Godwin C. Ugwunnadi, and Oluwatosin T. Mewomo*

\title{
On the proximal point algorithm and demimetric mappings in CAT(0) spaces
}

https://doi.org/10.1515/dema-2018-0022

Received June 5, 2018; accepted September 14, 2018

\begin{abstract}
In this paper, we introduce and study the class of demimetric mappings in CAT(0) spaces. We then propose a modified proximal point algorithm for approximating a common solution of a finite family of minimization problems and fixed point problems in CAT(0) spaces. Furthermore, we establish strong convergence of the proposed algorithm to a common solution of a finite family of minimization problems and fixed point problems for a finite family of demimetric mappings in complete CAT(0) spaces. A numerical example which illustrates the applicability of our proposed algorithm is also given. Our results improve and extend some recent results in the literature.
\end{abstract}

Keywords: demimetric mappings, minimization problem, CAT(0) spaces, fixed point problem

MSC: 47H06, 47H09, 47J05, 47J25

\section{Introduction}

Let $D$ be a nonempty subset of a metric space $(X, d)$. A point $x \in X$ is called a fixed point of a nonlinear mapping $T: D \rightarrow X$, if $x=T x$. We denote by $F(T)$ the set of fixed points of $T$. The mapping $T$ is said to be:

(i) nonexpansive, if for all $x, y \in D$,

$$
d(T x, T y) \leq d(x, y),
$$

(ii) quasi-nonexpansive, if $F(T) \neq \emptyset$ and for $y \in F(T), x \in D$, we have

$$
d(T x, y) \leq d(x, y),
$$

(iii) $k$-strictly pseudocontractive, if there exists $k \in[0,1)$, such that

$$
d^{2}(T x, T y) \leq d^{2}(x, y)+k[d(x, T x)+d(x, T y)]^{2} \text { for all } x, y \in D,
$$

(iv) $k$-demicontractive, if $F(T) \neq \emptyset$ and there exists $k \in[0,1)$, such that

$$
d^{2}(T x, y) \leq d^{2}(x, y)+k d^{2}(T x, x) \forall x \in D, y \in F(T),
$$

(v) generalized hybrid, if there exist $\alpha, \beta \in \mathbb{R}$, such that

$$
\alpha d^{2}(T x, T y)+(1-\alpha) d^{2}(x, T y) \leq \beta d^{2}(T x, y)+(1-\beta) d^{2}(x, y) \text { for all } x, y \in D .
$$

Kazeem O. Aremu: School of Mathematics, Statistics and Computer Science, University of KwaZulu-Natal, Durban, South Africa; E-mail: aremukazeemolalekan@gmail.com, 218081063@stu.ukzn.ac.za

Chinedu Izuchukwu: School of Mathematics, Statistics and Computer Science, University of KwaZulu-Natal, Durban, South Africa; E-mail: izuchukwu_c@yahoo.com, izuchukwuc@ukzn.ac.za

Godwin C. Ugwunnadi: Department of Mathematics, University of Eswatini, Kwaluseni, Eswatini;

E-mail: gc.ugwunnadi@mouau.edu.ng, ugwunnadi4u@yahoo.com

${ }^{\star}$ Corresponding Author: Oluwatosin T. Mewomo: School of Mathematics, Statistics and Computer Science, University of KwaZulu-Natal, Durban, South Africa; E-mail: mewomoo@ukzn.ac.za 
Clearly, the class of nonexpansive mappings (with nonempty fixed points set) is contained in the class of quasi-nonexpansive mappings, while the class of demicontractive mappings contains both the classes of nonexpansive and quasi-nonexpansive mappings. Moreover, there are several examples in the literature which show that the above inclusions are proper (see for example, [1] and the references therein).

Takahashi [2] (see also [3]) recently introduced a new class of nonlinear mappings in a Hilbert space, namely the class of demimetric mappings, which is defined as follows:

Let $H$ be a real Hilbert space and $D$ be a nonempty, closed and convex subset of $H$. A mapping $T: D \rightarrow H$ is called $k$-demimetric, if $F(T) \neq \emptyset$ and there exists $k \in(-\infty, 1)$, such that for any $x \in D$ and $y \in F(T)$, we have

$$
\langle x-y, x-T x\rangle \geq \frac{1-k}{2}\|x-T x\|^{2} .
$$

The class of $k$-demimetric mappings with $k \in(-\infty, 1)$ is a wide class of mappings known to cover the class of $k$-demicontractive mappings with $k \in[0,1)$, generalized hybrid mappings, the metric projections and the resolvents of maximal monotone operators in Hilbert spaces (see [3-5]). We note that the class of $k$-demimetric and $k$-demicontractive mappings are both quasi-generalizations of the class of $k$-strictly pseudocontractive mappings.

The approximation of fixed points of the above nonlinear mappings have been studied extensively by various authors in the settings of both Hilbert and Banach spaces (see [6-12]). The study has now been extended to nonlinear spaces, precisely, CAT(0) spaces. The pioneer work in fixed point theory in $\operatorname{CAT}(0)$ spaces was th work of Kirk [13]. After that Dhompongsa and Panyanak [14], Khan and Abass [15], Chan et al. [16], among others, continued to obtain interesting results on fixed point theory in CAT(0) spaces. Recently, Berg and Nikolaev [17] introduced an inner product-like notion in $\operatorname{CAT}(0)$ spaces called the quasilinearization mapping, which is defined as follows:

Let a pair $(a, b) \in X \times X$, denoted by $\overrightarrow{a b}$, be called a vector. The quasilinearization map $\langle.,\rangle:.(X \times X) \times(X \times X) \rightarrow$ $\mathbb{R}$ is defined by

$$
\langle\overrightarrow{a b}, \overrightarrow{c d}\rangle=\frac{1}{2}\left(d^{2}(a, d)+d^{2}(b, c)-d^{2}(a, c)-d^{2}(b, d)\right) \text {, for all } a, b, c, d \in X .
$$

It is not difficult to see that $\langle\overrightarrow{a b}, \overrightarrow{a b}\rangle=d^{2}(a, b),\langle\overrightarrow{b a}, \overrightarrow{c d}\rangle=-\langle\overrightarrow{a b}, \overrightarrow{c d}\rangle,\langle\overrightarrow{a b}, \overrightarrow{c d}\rangle=\langle\overrightarrow{a e}, \overrightarrow{c d}\rangle+\langle\overrightarrow{e b}, \overrightarrow{c d}\rangle$ and $\langle\overrightarrow{a b}, \overrightarrow{c d}\rangle=\langle\overrightarrow{c d}, \overrightarrow{a b}\rangle$, for all $a, b, c, d, e \in X$. Furthermore, a geodesic space $X$ is said to satisfy the CauchySchwarz inequality if

$$
\langle\overrightarrow{a b}, \overrightarrow{c d}\rangle \leq d(a, b) d(c, d),
$$

for all $a, b, c, d \in X$. It is well known that a geodesically connected space is a CAT(0) space if and only if it satisfies the Cauchy-Schwarz inequality [14].

Using the inner product-like notion, Liu and Chang [18] introduced the following class of demicontractivetype mappings in $\operatorname{CAT}(0)$ spaces:

Let $X$ be a CAT(0) space and $D$ be a nonempty subset of $X$. A mapping $T: D \rightarrow X$ is called demicontractive in the sense of [18], if $F(T) \neq \emptyset$ and there exists a constant $k \in(0,1)$, such that

$$
\langle\overrightarrow{T x y}, \overrightarrow{x y}\rangle \leq d^{2}(x, y)-k d^{2}(x, T x) \text {, for all } x \in D, y \in F(T) .
$$

Equivalently, $T: D \rightarrow X$ is called demicontractive in the sense of [18], if $F(T) \neq \emptyset$ and there exists a constant $k \in(0,1)$, such that

$$
d^{2}(T x, y) \leq d^{2}(x, y)+(1-2 k) d^{2}(x, T x), \text { for all } x \in D, y \in F(T) .
$$

Let $X$ be a CAT(0) space. A mapping $h: X \rightarrow(-\infty, \infty]$ is said to be

(i) convex if

$$
h(\lambda x \oplus(1-\lambda) y) \leq \lambda h(x)+(1-\lambda) h(y) \text { for all } x, y \in X, \lambda \in(0,1),
$$

(ii) proper, if $D:=\{x \in X: h(x)<+\infty\}$ is nonempty, where $D$ denotes the domain of $h$, 
(iii) lower semi-continuous at a point $x \in D$ if

$$
h(x) \leq \liminf _{n \rightarrow \infty} h\left(x_{n}\right),
$$

for each sequence $\left\{x_{n}\right\}$ in $D$, such that $\lim _{n \rightarrow \infty} x_{n}=x$,

(iv) lower semi-continuous on $D$ if it is lower semi-continuous at any point in $D$.

The Moreau-Yosida resolvent of a proper convex and lower semi-continuous function $h$ for any $\lambda>0$, is defined as follows:

$$
J_{\lambda h} X=\arg \min _{u \in X}\left[h(u)+\frac{1}{2 \lambda} d^{2}(u, x)\right]
$$

for all $x \in X$. Jost [19] showed that the mapping $J_{\lambda h}$ is well-defined and nonexpansive for all $\lambda>0$.

The minimization problem deals with finding minimizers of a convex functional, that is, the problem of finding a point $x \in X$, such that

$$
h(x)=\min _{u \in X} h(u) .
$$

The set of solutions (minimizers) that satisfy (1.6) is denoted by $\arg \min _{u \in X} h(u)$. We note from [19] that $F\left(J_{\lambda h}\right)=\arg \min _{u \in X} h(u)$.

The Proximal Point Algorithm (PPA) is a vital tool for solving problem (1.6). PPA was first introduced for Hilbert spaces by Martinet [20] in 1970 and Rockafellar [21] in 1976. After that several authors have also used PPA to obtain convergence results in Hilbert and Banach spaces (see [22]-[28]). The PPA in CAT(0) spaces started with the work of Bačák [29] in 2013. He introduced the following PPA for solving (1.6) in a CAT(0) space:

$$
x_{n+1}=\arg \min _{u \in X}\left[h(u) \oplus \frac{1}{2 \lambda_{n}} d^{2}\left(y, x_{n}\right)\right],
$$

for $n \in \mathbb{N}$, where $\lambda_{n}>0$, such that $\sum_{n=1}^{\infty} \lambda_{n}=\infty$. Bačák [29] obtained a $\Delta$-convergence result of (1.7) to a minimizer of $h$. In 2015, Chlomajiak et al. [30] considered the following iterative algorithm for finding a minimizer of a proper convex and lower semicontinuous function and common fixed points of two nonexpansive mappings in complete CAT(0) spaces:

$$
\left\{\begin{array}{l}
z_{n}=\arg \min _{u \in X}\left[h(u) \oplus \frac{1}{2 \lambda_{n}} d^{2}\left(u, x_{n}\right)\right], \\
y_{n}=\beta_{n} x_{n} \oplus\left(1-\beta_{n}\right) T_{1} z_{n}, \\
x_{n+1}=\alpha_{n} T_{1} x_{n} \oplus\left(1-\alpha_{n}\right) T_{2} y_{n} \text { for all } n \geq 1,
\end{array}\right.
$$

where $0<a \leq \alpha_{n}, \beta_{n} \leq b<1$ for all $n \geq 1$ and $\lambda_{n} \geq \lambda>0$ for all $n \geq 1$. They showed that the sequence $\left\{x_{n}\right\}$ $\Delta$-converges to an element of $\Gamma:=\arg \min _{u \in X} h(u) \cap F\left(T_{1}\right) \cap F\left(T_{2}\right)$, provided $\Gamma$ is nonempty.

Very recently, Lerkchaiyaphum and Phuengrattana [31] proposed the following modified PPA in CAT(0) spaces for finding a common minimizer of a finite family of proper convex and lower semicontinuous functions, and a common fixed point of a finite family of nonexpansive mappings in a CAT(0) space. More precisely, they proved the following theorem:

Theorem 1.1. Let $D$ be a nonempty closed convex subset of a complete CAT(O) space X. Let $\left\{h_{i}\right\}_{i=1}^{N}$ be a finite family of proper, convex and lower semicontinuous functions of $D$ into $(-\infty, \infty]$ and $\left\{T_{i}\right\}_{i=1}^{N}$ be a finite family of nonexpansive mappings of $D$ into itself. Suppose that $\mathcal{F}=\cap_{i=1}^{N} \arg \min _{u \in D} h_{i}(u) \cap \cap_{i=1}^{N} F\left(T_{i}\right)$ is nonempty. For $x_{1} \in D$, let $\left\{x_{n}\right\}$ be a sequence in $D$ defined by

$$
\left\{\begin{array}{l}
y_{n}^{(i)}=\arg \min _{u \in X}\left[h_{i}(u) \oplus \frac{1}{2 \lambda_{n}^{(i)}} d^{2}\left(u, x_{n}\right)\right], \\
z_{n}=\beta_{n}^{(0)} x_{n} \oplus \beta_{n}^{(1)} y_{n}^{(1)} \oplus \beta_{n}^{(2)} y_{n}^{(2)} \oplus \cdots \oplus \beta_{n}^{(N)} y_{n}^{(N)}, \\
w_{n}=\gamma_{n}^{(0)} z_{n} \oplus \gamma_{n}^{(1)} T_{1} z_{n}^{(1)} \oplus \gamma_{n}^{(2)} T_{2} z_{n}^{(2)} \oplus \cdots \oplus \gamma_{n}^{(N)} T_{N} z_{n}^{(N)}, \\
x_{n+1}=\alpha_{n} x_{n} \oplus\left(1-\alpha_{n}\right) w_{n} \text { for all } n \geq 1,
\end{array}\right.
$$


where $\left\{\alpha_{n}\right\},\left\{\beta_{n}^{(i)}\right\},\left\{\gamma_{n}^{(i)}\right\}$ are sequences in $[0,1]$, such that $0<a \leq \alpha_{n}, \beta_{n}^{(i)}, \gamma_{n}^{(i)} \leq b<1, \sum_{i=0}^{N} \beta_{n}^{(i)}=1$ and $\sum_{i=0}^{N} \gamma_{n}^{(i)}=1$ for all $n \geq 1$, and $\left\{\lambda_{n}^{(i)}\right\}$ is a sequence such that $\lambda_{n}^{(i)} \leq \lambda^{(i)}>0$ for all $n \geq 1, i=1,2, \cdots, N$. Then, $\left\{x_{n}\right\} \Delta$-converges to an element of $\mathcal{F}$.

Inspired by the works of Takahashi [3], Lerkchaiyaphum and Phuengrattana [31], we introduce the class of $k$-demimetric mappings in the framework of $\operatorname{CAT}(0)$ spaces and prove a strong convergence theorem for a common solution of a finite family of minimization problems and fixed point problems involving this class of mappings in complete CAT(0) spaces. Our results improve and extend the work of Takahashi [3], Chlomajiak et al. [30], Lerkchaiyaphum and Phuengrattana [31].

\section{Preliminaries}

Let $(X, d)$ be a metric space, $x, y \in X$ and $I=[0, d(x, y)]$. A curve $c$ (or simply a geodesic path) joining $x$ to $y$ is an isometry $c: I \rightarrow X$, such that $c(0)=x, c(d(x, y))=y$ and $d\left(c(t), c\left(t^{\prime}\right)=\left|t-t^{\prime}\right|\right.$ for all $t, t^{\prime} \in I$. The image of a geodesic path is called the geodesic segment, which is denoted by $[x, y]$ whenever it is unique. We say a metric space $X$ is a geodesic space if for every pair of points $x, y \in X$, there is a minimal geodesic from $x$ to $y$. A geodesic triangle $\Delta\left(x_{1}, x_{2}, x_{3}\right)$ in a geodesic metric space $(X, d)$ consists of three vertices (points in $X$ ) with unparameterized geodesic segments between each pair of vertices. For any geodesic triangle there is comparison (Alexandrov) triangle $\bar{\Delta} \subset \mathbb{R}^{2}$, such that $d\left(x_{i}, x_{j}\right)=d_{\mathbb{R}^{2}}\left(\bar{x}_{i}, \bar{x}_{j}\right)$, for $i, j \in\{1,2,3\}$.

A geodesic space $X$ is a CAT(0) space if the distance between an arbitrary pair of points on a geodesic triangle $\Delta$ does not exceed the distance between its corresponding pair of points on its comparison triangle $\bar{\Delta}$. If $\Delta$ and $\bar{\Delta}$ are geodesic and comparison triangles in $X$ respectively, then $\Delta$ is said to satisfy the $\operatorname{CAT}(0)$ inequality for all points $x, y$ of $\Delta$ and $\bar{x}, \bar{y}$ of $\bar{\Delta}$ if

$$
d(x, y)=d_{\mathbb{R}^{2}}(\bar{x}, \bar{y}) .
$$

Let $x, y, z$ be points in $X$ and $y_{0}$ be the midpoint of the segment $[y, z]$, then the CAT(0) inequality implies

$$
d^{2}\left(x, y_{0}\right) \leq \frac{1}{2} d^{2}(x, y)+\frac{1}{2} d^{2}(x, z)-\frac{1}{4} d(y, z) .
$$

For more properties of $\operatorname{CAT}(0)$ spaces, see [32-34] and the references therein.

Let $\left\{x_{n}\right\}$ be a bounded sequence in $X$ and $r\left(.,\left\{x_{n}\right\}\right): X \rightarrow[0, \infty)$ be a continuous mapping defined by $r\left(x,\left\{x_{n}\right\}\right)=\limsup _{n \rightarrow \infty} d\left(x, x_{n}\right)$. The asymptotic radius of $\left\{x_{n}\right\}$ is given by $r\left(\left\{x_{n}\right\}\right):=\inf \left\{r\left(x,\left\{x_{n}\right\}\right): x \in X\right\}$ while the asymptotic center of $\left\{x_{n}\right\}$ is the set $A\left(\left\{x_{n}\right\}\right)=\left\{x \in X: r\left(x,\left\{x_{n}\right\}\right)=r\left(\left\{x_{n}\right\}\right)\right\}$. It is known that in a Hadamard space $X, A\left(\left\{x_{n}\right\}\right)$ consists of exactly one point. A sequence $\left\{x_{n}\right\}$ in $X$ is said to be $\Delta$-convergent to a point $x \in X$ if $A\left(\left\{x_{n_{k}}\right\}\right)=\{x\}$ for every subsequence $\left\{x_{n_{k}}\right\}$ of $\left\{x_{n}\right\}$. In this case, we write $\Delta-\lim _{n \rightarrow \infty} x_{n}=x$ (see $[35,36])$.

Definition 2.1. Let $D$ be a nonempty closed and convex subset of a complete CAT(0) space $X$. A mapping $T: D \rightarrow D$ is said to be $\Delta$-demiclosed, if for any bounded sequence $\left\{x_{n}\right\}$ in $X$, such that $\Delta$ - $\lim _{n \rightarrow \infty} x_{n}=x$ and $\lim _{n \rightarrow \infty} d\left(x_{n}, T x_{n}\right)=0$, then $x=T x$.

Definition 2.2. Let $D$ be a nonempty closed and convex subset of a CAT(0) space $X$. The metric projection is a mapping $P_{D}: X \rightarrow D$ which assigns to each $x \in X$, the unique point $P_{D} x$ in $D$, such that

$$
d\left(x, P_{D} x\right)=\inf \{d(x, y): y \in D\} .
$$

Recall that a mapping $T$ is firmly nonexpansive (see [37]), if

$$
d^{2}(T x, T y) \leq\langle\overrightarrow{T x T y}, \overrightarrow{x y}\rangle \text { for all } x, y \in X .
$$


It follows from the Cauchy-Schwartz inequality that firmly nonexpansive mappings are nonexpansive. Metric projection mapping is an example of a firmly nonexpansive mapping (see [37, Corollary 3.8]). The notion of firmly nonexpansive mappings was first introduced in nonlinear settings in [38]. We also remark here that (2.3) corresponds to property $\left(P_{2}\right)$ (Definition 2.7) of [39].

We give some known and useful results which will be needed in the proof of our main theorem. In the sequel, we denote strong and $\Delta$-convergence by " $\rightarrow$ " and $" \rightarrow$, respectively.

Lemma 2.3. [14] Let $X$ be a CAT(0) space, then for each $x, y \in X$ and $t \in[0,1]$, there exists a unique point $z \in[x, y]$, such that

$$
d(z, x)=(1-t) d(x, y) \text { and } d(z, y)=t d(x, y) .
$$

In this case, we write $z=t x \oplus(1-t) y$.

Lemma 2.4. [19] Let $(X, d)$ be a complete CAT(0) space and $h: X \rightarrow(-\infty, \infty]$ be proper, convex and lower semi-continuous. Then the following identity holds:

$$
J_{\lambda h} x=J_{\mu h}\left(\frac{\lambda-\mu}{\lambda} J_{\lambda h} x \oplus \frac{\mu}{\lambda} x\right)
$$

for all $x \in X$ and $\lambda \geq \mu>0$.

Lemma 2.5. $[14,40]$ Let $X$ be a CAT(O) space. Then for all $x, y, z \in X$ and all $t \in[0,1]$, we have

1. $d(t x \oplus(1-t) y, z) \leq t d(x, z)+(1-t) d(y, z)$,

2. $d^{2}(t x \oplus(1-t) y, z) \leq t d^{2}(x, z)+(1-t) d^{2}(y, z)-t(1-t) d^{2}(x, y)$,

3. $d^{2}(z, t x \oplus(1-t) y) \leq t^{2} d^{2}(z, x)+(1-t)^{2} d^{2}(z, y)+2 t(1-t)\langle\overrightarrow{z x}, \overrightarrow{z y}\rangle$.

Lemma 2.6. [41] Let $X$ be a complete $C A T(0)$ space. For any $t \in[0,1]$ and $u, v \in X$, let $u_{t}=t u \oplus(1-t) v$. Then, for all $x, y \in X$, we have

$$
\left\langle\overrightarrow{u_{t} x}, \overrightarrow{u y}\right\rangle \leq t\langle\overrightarrow{u x}, \overrightarrow{u y}\rangle+(1-t)\langle\overrightarrow{v x}, \overrightarrow{u y}\rangle
$$

Lemma 2.7. [42] Let $X$ be a CAT(O) space and $z \in X$. Let $x_{1}, \cdots, x_{N} \in X$ and $\gamma_{1}, \cdots, \gamma_{N}$ be real numbers in $[0,1]$, such that $\sum_{i=1}^{N} \gamma_{i}=1$. Then the following inequality holds:

$$
\sum_{i=1}^{N} \oplus \gamma_{i} d^{2}\left(x_{i}, z\right) \leq \sum_{i=1}^{N} \gamma_{i} d^{2}\left(x_{i}, z\right)-\sum_{i, j=1, i \neq j}^{N} \gamma_{i} \gamma_{j} d^{2}\left(x_{i}, x_{j}\right) .
$$

Lemma 2.8. [43] Every bounded sequence in a complete CAT(O) space has a $\Delta$-convergent subsequence.

Lemma 2.9. [44] Let $X$ be a complete CAT(O) space, $\left\{x_{n}\right\}$ be a bounded sequence in $X$ and $x \in X$. Then $\left\{x_{n}\right\}$ $\Delta$-converges to $x$ if and only if $\lim \sup \left\langle\overrightarrow{x_{n} x}, \overrightarrow{y x}\right\rangle \leq 0$ for all $y \in X$.

Lemma 2.10. [45] Let $X$ be a complete CAT(O) space and $T: X \rightarrow X$ be a nonexpansive mapping. Then $T$ is $\Delta$-demiclosed.

Lemma 2.11. [46] Let $X$ be a complete CAT(0) space and $h: X \rightarrow(-\infty, \infty$ ] be a proper, convex and lower semi-continuous mapping. Then, for all $x, y \in X$ and $\lambda>0$, we have

$$
\frac{1}{2 \lambda} d^{2}\left(J_{\lambda h} x, y\right)-\frac{1}{2 \lambda} d^{2}(x, y)+\frac{1}{2 \lambda} d^{2}\left(x, J_{\lambda h} x\right)+h\left(J_{\lambda h} x\right) \leq h(y) .
$$

Lemma 2.12. [47] Let $\left\{a_{n}\right\}$ be a sequence of non-negative real numbers satisfying

$$
a_{n+1} \leq\left(1-\alpha_{n}\right) a_{n}+\alpha_{n} \delta_{n}+\gamma_{n}, \quad n \geq 0,
$$


where $\left\{\alpha_{n}\right\},\left\{\delta_{n}\right\}$ and $\left\{\gamma_{n}\right\}$ satisfy the following conditions:

(i) $\left\{\alpha_{n}\right\} \subset[0,1], \Sigma_{n=0}^{\infty} \alpha_{n}=\infty$,

(ii) $\lim \sup _{n \rightarrow \infty} \delta_{n} \leq 0$,

(iii) $\gamma_{n} \geq 0(n \geq 0), \Sigma_{n=0}^{\infty} \gamma_{n}<\infty$.

Then $\lim _{n \rightarrow \infty} a_{n}=0$.

Lemma 2.13. [48] Let $\left\{a_{n}\right\}$ be a sequence of real numbers, such that there exists a subsequence $\left\{n_{j}\right\}$ of $\{n\}$ with $a_{n_{j}}<a_{n_{j}+1}$ for all $j \in \mathbb{N}$. Then there exists a nondecreasing sequence $\left\{m_{k}\right\} \subset \mathbb{N}$, such that $m_{k} \rightarrow \infty$ and the following properties are satisfied by all (sufficiently large) numbers $k \in \mathbb{N}$ :

$$
a_{m_{k}} \leq a_{m_{k}+1} \text { and } a_{k} \leq a_{m_{k}+1} .
$$

In fact, $m_{k}=\max \left\{i \leq k: a_{i}<a_{i+1}\right\}$.

\section{Main results}

We first give the definition of a $k$-demimetric mapping in a CAT(0) space. We begin with the following facts which led to our definition.

If $T$ is a $k$-demicontractive mapping with $k \in[0,1)$, then

$$
d^{2}(T x, y) \leq d^{2}(x, y)+k d^{2}(x, T x) \text { for all } x \in X, y \in F(T) .
$$

Also, by definition of quasilinearization mapping (see (1.2)), we obtain that

$$
2\langle\overrightarrow{x y}, \overrightarrow{x T x}\rangle=d^{2}(x, y)+d^{2}(T x, x)-d^{2}(T x, y) .
$$

That is,

$$
d^{2}(T x, y)=d^{2}(x, y)+d^{2}(T x, x)-2\langle\overrightarrow{x T x}, \overrightarrow{x y}\rangle,
$$

which implies from (3.1) that

$$
\langle\overrightarrow{x y}, \overrightarrow{x T x}\rangle \geq \frac{1-k}{2} d^{2}(x, T x) .
$$

Motivated by (3.2) above, we define the demimetric mapping in a CAT(0) space as follows:

Definition 3.1. Let $X$ be a CAT(0) space and $D$ be a nonempty closed and convex subset of $X$. A mapping $T: D \rightarrow X$ is said to be $k$-demimetric if $F(T) \neq \emptyset$ and there exists $k \in(-\infty, 1)$, such that

$$
\langle\overrightarrow{x y}, \overrightarrow{x T x}\rangle \geq \frac{1-k}{2} d^{2}(x, T x) \text { for all } x \in X, y \in F(T) .
$$

Clearly, the class of $k$-demimetric mappings with $k \in(-\infty, 1)$ contains the class of $k$-demicontractive mappings with $k \in[0,1)$.

Remark 3.2. If $T$ is a generalized hybrid mapping with $F(T) \neq \emptyset$, then for $x \in D$ and $y \in F(T)$ we obtain that

$$
\alpha d^{2}(T x, y)+(1-\alpha) d^{2}(x, y) \leq \beta d^{2}(T x, y)+(1-\beta) d^{2}(x, y),
$$

which implies that

$$
d^{2}(T x, y) \leq d^{2}(x, y)
$$

Now, from (3.4) and the definition of quasilinearization, we obtain that

$$
2\langle\overrightarrow{x y}, \overrightarrow{x T x}\rangle=d^{2}(x, T x)+d^{2}(x, y)-d^{2}(y, T x) \geq d^{2}(x, T x)+d^{2}(x, y)-d^{2}(x, y),
$$


which implies that

$$
\langle\overrightarrow{x y}, \overrightarrow{x T x}\rangle \geq \frac{1-0}{2} d^{2}(x, T x) .
$$

Also, $T$ is firmly nonexpansive if

$$
d^{2}(T x, T y) \leq\langle\overrightarrow{x y}, \overrightarrow{T x T y}\rangle \text { for all } x, y \in D .
$$

If $F(T) \neq \emptyset$, then for all $x \in D$ and $y \in F(T)$, we have that

$$
d^{2}(T x, y) \leq\langle\overrightarrow{x y}, \overrightarrow{T x y}\rangle .
$$

Therefore, the following implications hold:

$$
\begin{aligned}
& \langle\overrightarrow{T x y}, \overrightarrow{T x y}\rangle \leq\langle\overrightarrow{T x y}, \overrightarrow{x y}\rangle \\
& \Rightarrow\langle\overrightarrow{y T x}, \overrightarrow{y T x}\rangle+\langle\overrightarrow{y T x}, \overrightarrow{x y}\rangle \leq 0 \\
& \Rightarrow\langle\overrightarrow{y T x}, \overrightarrow{y x}\rangle+\langle y T x, \overrightarrow{x T x}\rangle+\langle\overrightarrow{y T x}, \overrightarrow{x y}\rangle \leq 0 \\
& \Rightarrow\langle\overrightarrow{T x y}, \overrightarrow{x y}\rangle+\langle\overrightarrow{y T x}, \overrightarrow{x y}\rangle+\langle\overrightarrow{y x}, \overrightarrow{x T x}\rangle+\langle\overrightarrow{x T x}, \overrightarrow{x T x}\rangle \leq 0 \\
& \Rightarrow\langle\overrightarrow{T x T x}, \overrightarrow{x y}\rangle+d^{2}(x, T x) \leq\langle\overrightarrow{x y}, \overrightarrow{x T x}\rangle, \\
& \Rightarrow\langle\overrightarrow{x y}, \overrightarrow{x T x}\rangle+\langle\overrightarrow{x y}, \overrightarrow{T x T x}\rangle \geq d^{2}(x, T x),
\end{aligned}
$$

which implies that

$$
\langle\overrightarrow{x y}, \overrightarrow{x T x}\rangle \geq \frac{1-(-1)}{2} d^{2}(x, T x) .
$$

Thus, (3.6) and (3.5) show that generalized hybrid mappings with nonempty fixed point sets and firmly nonexpansive mappings with nonempty fixed point sets are 0 and -1 demimetric mappings respectively. Since metric projection mappings are an example of firmly nonexpansive mappings, then they are demimetric mappings.

Example 3.3. Let $T:[0,1] \rightarrow[0,1]$ be defined by $T x=x-x^{j}, j \geq 1$. Then $T$ is $k$-demimetric with $k=-1$.

Proof. Clearly, $F(T)=\{0\}$. Now, for all $x \in[0,1]$ and $j \geq 1$, we obtain that

$$
\begin{aligned}
\langle x-0, x-T x\rangle & =\left\langle x, x^{j}\right\rangle \\
& =\frac{1}{2}\left[|x|^{2}+\left|x^{j}\right|^{2}-\left|x-x^{j}\right|^{2}\right] \\
& =\frac{1}{2}\left[|x|^{2}+\left|x^{j}\right|^{2}-|x|^{2}+2|x|\left|x^{j}\right|^{2}-\left|x^{j}\right|^{2}\right] \\
& \geq \frac{1}{2}\left[2\left|x^{j}\right|\left|x^{j}\right|\right]=\left|x^{j}\right|^{2} .
\end{aligned}
$$

That is,

$$
\langle x-0, x-T x\rangle \geq \frac{1-(-1)}{2}\left|x^{j}\right|^{2} .
$$

Hence, we have that $\langle x-0, x-T x\rangle \geq \frac{1-(-1)}{2}|x-T x|^{2}$.

We now study some fixed point properties of $k$-demimetric mappings in CAT(0) spaces.

Proposition 3.4. Let $X$ be a complete CAT(O) space and $T: X \rightarrow X$ be a $k$-demimetric mapping with $k \in$ $(-\infty, 1)$, such that $F(T)$ is nonempty. Then $F(T)$ is closed and convex. 
Proof. We first show that $F(T)$ is closed. Let $\left\{x_{n}\right\}$ be a sequence in $F(T)$, such that $\left\{x_{n}\right\}$ converges to $x^{\star}$. Then from Definition 3.5, we have that

$$
\left\langle\overrightarrow{x^{\star} x_{n}}, \overrightarrow{x^{\star} T x^{*}}\right\rangle \geq \frac{1-k}{2} d^{2}\left(x^{\star}, T x^{\star}\right),
$$

which implies by the Cauchy-Schwarz inequality that

$$
d\left(x^{\star}, x_{n}\right) d\left(x^{\star}, T x^{\star}\right) \geq \frac{1-k}{2} d^{2}\left(x^{\star}, T x^{\star}\right) .
$$

Taking limits on both sides of (3.7), we obtain that $\frac{1-k}{2} d^{2}\left(x^{\star}, T x^{\star}\right) \leq 0$. By the condition on $k$, we obtain that $d\left(x^{\star}, T x^{\star}\right)=0$. Thus, $x^{\star} \in F(T)$. Therefore, $F(T)$ is closed.

Next, we show that $F(T)$ is convex. For this, let $x, y \in F(T)$. Then it suffices to show that $(t x \oplus(1-t) y) \in$ $F(T)$, for $t \in[0,1]$. Set $z=t x \oplus(1-t) y, t \in[0,1]$. Then by Definition 3.1, we obtain from Lemma 2.6 that

$$
\begin{aligned}
d^{2}(z, T z) & =\langle\overrightarrow{z T z}, \overrightarrow{z T z}\rangle \\
& =\langle\overrightarrow{(t x \oplus(1-t) y) T z}, \overrightarrow{z T z}\rangle \\
& \leq t\langle\overrightarrow{x T z}, \overrightarrow{z T z}\rangle+(1-t)\langle\overrightarrow{y T z}, \overrightarrow{z T z}\rangle \\
& =t[\langle\overrightarrow{x z}, \overrightarrow{z T z}\rangle+\langle\overrightarrow{z T z}, \overrightarrow{z T z}\rangle]+(1-t)[\langle\overrightarrow{y z}, \overrightarrow{z T z}\rangle+\langle\overrightarrow{z T z}, \overrightarrow{z T z}\rangle] \\
& \leq \frac{t(k-1)}{2} d^{2}(z, T z)+t d^{2}(z, T z)+\frac{(1-t)(k-1)}{2} d^{2}(z, T z)+(1-t) d^{2}(z, T z) \\
& =\frac{k-1}{2} d^{2}(z, T z)+d^{2}(z, T z),
\end{aligned}
$$

which implies that $\frac{k-1}{2} d^{2}(z, T z) \geq 0$. By the condition on $k$, we obtain that $d^{2}(z, T z) \leq 0$. Hence, $z=T z$ and this yields the desired conclusion.

The following Lemma is a cardinal property of all kinds of mappings derived from strictly pseudocontractions. The Lemma first appeared in the setting of Hilbert spaces [[49], Theorem 2]. We state the lemma for $k$-demimetric mappings in a $\mathrm{CAT}(0)$ space setting and give the proof for completeness.

Lemma 3.5. Let $X$ be a CAT(O) space and $T: X \rightarrow X$ be a $k$-demimetric mapping with $k \in(-\infty, \lambda]$ and $\lambda \in(0,1)$, such that $F(T)$ is nonempty. Suppose that $T_{\lambda} x=\lambda x \oplus(1-\lambda) T x$. Then $T_{\lambda}$ is quasi-nonexpansive and $F\left(T_{\lambda}\right)=F(T)$.

Proof. Let $x \in X$ and $z \in F(T)$. Then, from Definition 3.1 and Lemma 2.6 we obtain that

$$
\begin{aligned}
& \left.\left\langle\overrightarrow{z x}, \overrightarrow{x T_{\lambda} x}\right\rangle=\langle\overrightarrow{z x}, \overrightarrow{x(\lambda x \oplus(1-\lambda) T x})\right\rangle \\
& =\langle\overrightarrow{(\lambda x \oplus(1-\lambda) T x) x}, \overrightarrow{x z}\rangle \\
& \leq \lambda\langle\overrightarrow{x x}, \overrightarrow{x z}\rangle+(1-\lambda)\langle\overrightarrow{T x x}, \overrightarrow{x z}\rangle \\
& =(1-\lambda)\langle\overrightarrow{x z}, \overrightarrow{T x x}\rangle \\
& \leq \frac{(1-\lambda)^{2}(k-1)}{2(1-\lambda)} d^{2}(x, T x) .
\end{aligned}
$$

Now, from Lemma 2.3, we obtain that $d^{2}\left(x, T_{\lambda} x\right)=(1-\lambda)^{2} d^{2}(x, T x)$. Substituting this in (3.8), we obtain

$$
\left\langle\overrightarrow{z x}, \overrightarrow{x T_{\lambda} x}\right\rangle \leq \frac{k-1}{2(1-\lambda)} d^{2}\left(x, T_{\lambda} x\right)
$$

which implies that

$$
\begin{aligned}
\left\langle\overrightarrow{x z}, \overrightarrow{x T_{\lambda} x}\right\rangle & \geq \frac{1-k}{2(1-\lambda)} d^{2}\left(x, T_{\lambda} x\right) \\
& \geq \frac{1}{2} d^{2}\left(x, T_{\lambda} x\right) .
\end{aligned}
$$


Thus, by (1.2), we obtain that

$$
d^{2}\left(x, T_{\lambda} x\right)+d^{2}(z, x)-d^{2}\left(z, T_{\lambda} x\right) \geq d^{2}\left(x, T_{\lambda} x\right) .
$$

That is,

$$
d^{2}\left(z, T_{\lambda} x\right) \leq d^{2}(z, x)
$$

Hence, $T_{\lambda}$ is quasi-nonexpansive.

We next show that $F\left(T_{\lambda}\right)=F(T)$. Let $x \in F\left(T_{\lambda}\right)$, then $x=T_{\lambda} x$. So,

$$
\begin{aligned}
d(x, T x) & =d(\lambda x \oplus(1-\lambda) T x, T x) \\
& \leq \lambda d(x, T x),
\end{aligned}
$$

which implies that $(1-\lambda) d(x, T x) \leq 0$. Since $\lambda<1$, we obtain that $d(x, T x) \leq 0$.

Therefore, $x \in F(T)$, and thus $F\left(T_{\lambda}\right) \subseteq F(T)$.

Conversely, let $x \in F(T)$, then $x=T x$. By Lemma 2.5, we obtain

$$
\begin{aligned}
d\left(x, T_{\lambda} x\right) & =d(T x, \lambda x \oplus(1-\lambda) T x) \\
& \leq \lambda d(T x, x)+(1-\lambda) d(T x, T x) \\
& =0,
\end{aligned}
$$

which implies that $d\left(x, T_{\lambda} x\right)=0$. Thus, $x \in F\left(T_{\lambda}\right)$ and therefore $F(T) \subseteq F\left(T_{\lambda}\right)$. Hence, we obtain the desired result.

Theorem 3.6. Let $D$ be a nonempty closed and convex subset of a complete CAT(O) space $X$, and $h_{i}: X \rightarrow$ $(-\infty, \infty], i=1, \cdots, N$ be a finite family of proper, convex and lower semi-continuous functions. Let $T_{i}: D \rightarrow D$, $i=1, \cdots, N$ be a finite family of $k_{i}$-demimetric mappings with $k_{i} \in(-\infty, \lambda]$ and $\lambda \in(0,1)$. Suppose that $\Gamma=\left(\cap_{i=1}^{N} \operatorname{argmin}_{u \in X} h_{i}(u)\right) \cap\left(\cap_{i=1}^{N} F\left(T_{i}\right)\right)$ is nonempty and $\left\{x_{n}\right\}$ is a sequence generated for arbitrary $x_{1}, u \in X$ by

$$
\left\{\begin{array}{l}
v_{n}=\left(1-t_{n}\right) x_{n} \oplus t_{n} u, \\
y_{n}=J_{r_{n} h_{1}} \circ J_{r_{n} h_{2}} \circ \cdots \circ J_{r_{n} h_{N}} v_{n}, \\
z_{n}=P_{D}\left(\beta_{n}^{(0)} v_{n} \oplus \beta_{n}^{(1)} y_{n} \oplus \cdots \oplus \beta_{n}^{(N)} y_{n}\right), \\
w_{n}=\gamma_{n}^{(0)} z_{n} \oplus \gamma_{n}^{(1)} T_{1 \lambda} z_{n} \oplus \gamma_{n}^{(1)} T_{2 \lambda} z_{n} \cdots \oplus \gamma_{n}^{(N)} T_{N \lambda} z_{n}, \\
x_{n+1}=\alpha_{n} v_{n} \oplus\left(1-\alpha_{n}\right) w_{n} \text { for all } n \geq 1,
\end{array}\right.
$$

where $T_{i \lambda} x=\lambda x \oplus(1-\lambda) T_{i} x$, such that $T_{i \lambda}$ are $\Delta$-demiclosed for each $i=1,2, \ldots, N$. Suppose that $\left\{t_{n}\right\},\left\{\alpha_{n}\right\}$, $\left\{\beta_{n}^{(i)}\right\}$ and $\left\{\gamma_{n}^{(i)}\right\}$ are sequences in [0,1], such that the following conditions are satisfied:

$C 1: 0<a \leq \alpha_{n}, \beta_{n}^{(i)}, \gamma_{n}^{(i)} \leq b<1, \sum_{i=0}^{N} \beta_{n}^{(i)}=1$ and $\sum_{i=0}^{N} \gamma_{n}^{(i)}=1$ for all $n \geq 1$,

$C 2: \lim _{n \rightarrow \infty} t_{n}=0, \sum_{n=1}^{\infty} t_{n}=\infty$,

C3: $\left\{r_{n}\right\}$ is a sequence of real numbers, such that $r_{n} \geq r>0$ for all $n \geq 1$.

Then, the sequence $\left\{x_{n}\right\}$ converges strongly to a point in $\Gamma$.

Proof. Let $p \in \Gamma$, from Lemma 3.5, we obtain that $p=T_{i \lambda} p$. Also, we have that $p=J_{r_{n} h_{i}} p, i=1,2, \cdots, N$. Thus, we obtain from (3.9), Lemma 2.7 and Lemma 3.5 that

$$
\begin{aligned}
d\left(w_{n}, p\right) & =d\left(\gamma_{n}^{(0)} z_{n} \oplus \gamma_{n}^{(1)} T_{1 \lambda} z_{n} \oplus \cdots \oplus \gamma_{n}^{(N)} T_{N \lambda} z_{n}, p\right) \\
& \leq \gamma_{n}^{(0)} d\left(z_{n}, p\right)+\sum_{i=1}^{N} \gamma_{n}^{(i)} d\left(T_{i \lambda} z_{n}, p\right) \\
& \leq \gamma_{n}^{(0)} d\left(z_{n}, p\right)+\sum_{i=1}^{N} \gamma_{n}^{(i)} d\left(z_{n}, p\right) \\
& =d\left(z_{n}, p\right) .
\end{aligned}
$$


From (3.9) and (3.10), we obtain

$$
\begin{aligned}
d\left(z_{n}, p\right) & \leq d\left(\beta_{n}^{(0)} v_{n} \oplus \beta_{n}^{(1)} y_{n} \oplus \cdots \oplus \beta_{n}^{(N)} y_{n}, p\right) \\
& \leq \beta_{n}^{(0)} d\left(v_{n}, p\right)+\sum_{i=1}^{N} \beta_{n}^{(i)} d\left(y_{n}, p\right) \\
& \leq \beta_{n}^{(0)} d\left(v_{n}, p\right)+\sum_{i=1}^{N} \beta_{n}^{(i)} d\left(J_{r_{n} h_{1}} \circ J_{r_{n} h_{2}} \cdots \circ J_{r_{n} h_{N}} v_{n}, p\right) \\
& \leq \beta_{n}^{(0)} d\left(v_{n}, p\right)+\sum_{i=1}^{N} \beta_{n}^{(i)} d\left(v_{n}, p\right) \\
& =d\left(v_{n}, p\right) .
\end{aligned}
$$

From (3.9), (3.10) and (3.11), we have that

$$
\begin{aligned}
d\left(x_{n+1}, p\right) & =d\left(\alpha_{n} v_{n} \oplus\left(1-\alpha_{n}\right) w_{n}, p\right) \\
& \leq \alpha_{n} d\left(v_{n}, p\right)+\left(1-\alpha_{n}\right) d\left(w_{n}, p\right) \\
& \leq \alpha_{n} d\left(v_{n}, p\right)+\left(1-\alpha_{n}\right) d\left(z_{n}, p\right) \\
& \leq \alpha_{n} d\left(v_{n}, p\right)+\left(1-\alpha_{n}\right) d\left(v_{n}, p\right) \\
& =d\left(v_{n}, p\right) \\
& =d\left(\left(1-t_{n}\right) x_{n} \oplus t_{n}, p\right) \\
& \leq\left(1-t_{n}\right) d\left(x_{n}, p\right)+t_{n} d(u, p) \\
& \leq \max \left\{d\left(x_{n}, p\right), d(u, p)\right\},
\end{aligned}
$$

which implies by induction that

$$
d\left(x_{n+1}, p\right) \leq \max \left\{d\left(x_{1}, p\right), d(u, p)\right\}, \text { for all } n \geq 1 .
$$

Hence $d\left(x_{n}, p\right)$ is bounded, and so are $\left\{v_{n}\right\},\left\{z_{n}\right\},\left\{w_{n}\right\}$ and $\left\{y_{n}\right\}$.

Now from (3.9), (3.10), (3.11), Lemma 2.5 and Lemma 2.7, we have

$$
\begin{aligned}
d^{2}\left(x_{n+1}, p\right)= & d^{2}\left(\alpha_{n} v_{n} \oplus\left(1-\alpha_{n}\right) w_{n}, p\right) \\
\leq & \alpha_{n} d^{2}\left(v_{n}, p\right)+\left(1-\alpha_{n}\right) d^{2}\left(w_{n}, p\right)-\alpha\left(1-\alpha_{n}\right) d^{2}\left(v_{n}, w_{n}\right) \\
\leq & \alpha_{n} d^{2}\left(v_{n}, p\right)+\left(1-\alpha_{n}\right)\left[\gamma_{n}^{(0)} d^{2}\left(z_{n}, p\right)+\sum_{i=1}^{N} \gamma_{n}^{(i)} d^{2}\left(T_{i \lambda} z_{n}, p\right)-\sum_{i=1}^{N} \gamma_{n}^{(0)} \gamma_{n}^{(i)} d^{2}\left(z_{n}, T_{i \lambda} z_{n}\right)\right. \\
& \left.-\sum_{i=1, i \neq j}^{N} \gamma_{n}^{(i)} \gamma_{n}^{(j)} d^{2}\left(T_{i \lambda} z_{n}, T_{j \lambda} z_{n}\right)\right]-\alpha_{n}\left(1-\alpha_{n}\right) d^{2}\left(v_{n}, w_{n}\right) \\
\leq & \alpha_{n} d^{2}\left(v_{n}, p\right)+\left(1-\alpha_{n}\right)\left[\gamma_{n}^{(0)} d^{2}\left(z_{n}, p\right)+\sum_{i=1}^{N} \gamma_{n}^{(i)} d^{2}\left(z_{n}, p\right)-\sum_{i=1}^{N} \gamma_{n}^{(0)} \gamma_{n}^{(i)} d^{2}\left(z_{n}, T_{i \lambda} z_{n}\right)\right. \\
& \left.-\sum_{i=1, i \neq j}^{N} \gamma_{n}^{(i)} \gamma_{n}^{(j)} d^{2}\left(T_{i \lambda_{i}} z_{n}, T_{j \lambda} z_{n}\right)\right]-\alpha_{n}\left(1-\alpha_{n}\right) d^{2}\left(v_{n}, w_{n}\right) \\
\leq & \alpha_{n} d^{2}\left(v_{n}, p\right)+\left(1-\alpha_{n}\right)\left[d^{2}\left(z_{n}, p\right)-\sum_{i=1}^{N} \gamma_{n}^{(0)} \gamma_{n}^{(i)} d^{2}\left(z_{n}, T_{i \lambda} z_{n}\right)\right]-\alpha_{n}\left(1-\alpha_{n}\right) d^{2}\left(v_{n}, w_{n}\right) \\
\leq & \alpha_{n} d^{2}\left(v_{n}, p\right)+\left(1-\alpha_{n}\right)\left[\beta_{n}^{(0)} d^{2}\left(v_{n}, p\right)+\sum_{i=1}^{N} \beta_{n}^{(i)} d^{2}\left(y_{n}, p\right)-\sum_{i=1}^{N} \beta_{n}^{(0)} \beta_{n}^{(i)} d^{2}\left(v_{n}, y_{n}\right)\right. \\
& \left.-\sum_{i=1, i \neq j}^{N} \beta_{n}^{(i)} \beta_{n}^{(j)} d^{2}\left(y_{n}^{(i)}, y_{n}^{(j)}\right)\right]-\alpha_{n}\left(1-\alpha_{n}\right) \sum_{i=1}^{N} \gamma_{n}^{(0)} \gamma_{n}^{(i)} d^{2}\left(z_{n}, T_{i \lambda} z_{n}\right)-\alpha_{n}\left(1-\alpha_{n}\right) d^{2}\left(v_{n}, w_{n}\right)
\end{aligned}
$$




$$
\begin{aligned}
& d^{2}\left(v_{n}, p\right)-\left(1-\alpha_{n}\right) \sum_{i=1}^{N} \beta_{n}^{(0)} \beta_{n}^{(i)} d^{2}\left(v_{n}, y_{n}\right)-\left(1-\alpha_{n}\right) \sum_{i=1, i \neq j}^{N} \beta_{n}^{(i)} \beta_{n}^{(j)} d^{2}\left(y_{n}^{(i)}, y_{n}^{(j)}\right) \\
& \quad-\left(1-\alpha_{n}\right) \sum_{i=1}^{N} \gamma_{n}^{(0)} \gamma_{n}^{(i)} d^{2}\left(z_{n}, T_{i \lambda} z_{n}\right)-\alpha_{n}\left(1-\alpha_{n}\right) d^{2}\left(v_{n}, w_{n}\right) \\
& \leq\left(1-t_{n}\right) d^{2}\left(x_{n}, p\right)+t_{n} d^{2}(u, p)-t_{n}\left(1-t_{n}\right) d^{2}\left(u, x_{n}\right)-\left(1-\alpha_{n}\right) \sum_{i=1}^{N} \beta_{n}^{(0)} \beta_{n}^{(i)} d^{2}\left(v_{n}, y_{n}\right) \\
& \quad-\left(1-\alpha_{n}\right) \sum_{i=1}^{N} \gamma_{n}^{(0)} \gamma_{n}^{(i)} d^{2}\left(z_{n}, T_{i \lambda} z_{n}\right)-\alpha_{n}\left(1-\alpha_{n}\right) d^{2}\left(v_{n}, w_{n}\right) \\
& \leq\left(1-t_{n}\right) d^{2}\left(x_{n}, p\right)+t_{n} d^{2}(u, p)-t_{n}\left(1-t_{n}\right) d^{2}\left(u, x_{n}\right)-\alpha_{n}\left(1-\alpha_{n}\right) d^{2}\left(v_{n}, w_{n}\right) .
\end{aligned}
$$

From (3.5) and condition C2, we obtain that

$$
d\left(v_{n}, x_{n}\right) \leq t_{n} d\left(u, x_{n}\right) \rightarrow 0, \quad \text { as } n \rightarrow \infty .
$$

Now we divide the rest of the proof into two cases:

Case 1: Assume that $\left\{d^{2}\left(x_{n}, p\right)\right\}$ is a monotonically non-increasing sequence. Clearly, $\left\{d^{2}\left(x_{n}, p\right)\right\}$ is convergent and

$$
d^{2}\left(x_{n}, p\right)-d^{2}\left(x_{n+1}, p\right) \rightarrow 0, \quad \text { as } n \rightarrow \infty
$$

So from (3.13), we have

$$
\begin{aligned}
\alpha_{n}(1-\alpha) d^{2}\left(v_{n}, w_{n}\right) & \leq\left(1-t_{n}\right) d^{2}\left(x_{n}, p\right)+t_{n} d^{2}(u, p)-d^{2}\left(x_{n+1}, p\right) \\
& =t_{n}\left[d^{2}(u, p)-d^{2}\left(x_{n}, p\right)\right]+d^{2}\left(x_{n}, p\right)-d^{2}\left(x_{n+1}, p\right),
\end{aligned}
$$

which implies by condition $\mathrm{C} 2$ that

$$
\lim _{n \rightarrow \infty} d\left(v_{n}, w_{n}\right)=0
$$

Similarly,

$$
\left(1-\alpha_{n}\right) \sum_{i=1}^{N} \gamma_{n}^{(0)} \gamma_{n}^{(i)} d^{2}\left(z_{n}, T_{\lambda} z_{n}\right) \leq t_{n}\left[d^{2}(u, p)-d\left(x_{n}, p\right)\right]+d^{2}\left(x_{n}, p\right)-d^{2}\left(x_{n+1}, p\right) \rightarrow 0, \quad \text { as } n \rightarrow \infty .
$$

Hence, by condition C2, we obtain that

$$
\left(1-\alpha_{n}\right) \sum_{i=1}^{N} \gamma_{n}^{(0)} \gamma_{n}^{(i)} d^{2}\left(z_{n}, T_{i \lambda} z_{n}\right) \rightarrow 0
$$

and thus,

$$
\lim _{n \rightarrow \infty} d\left(z_{n}, T_{i \lambda} z_{n}\right)=0, i=1,2, \cdots, N .
$$

In a similar way, from (3.11) we obtain that

$$
\lim _{n \rightarrow \infty} d\left(v_{n}, y_{n}\right)=\lim _{n \rightarrow \infty} d\left(J_{r_{n} h_{1}} \circ \cdots \circ J_{r_{n} h_{N}} v_{n}, v_{n}\right)=0 .
$$

Let $c_{n}^{(i)}=J_{r_{n} h_{i}} c_{n}^{(i+1)}, i=1,2, \cdots, N$, where $c_{n}^{(N+1)}=v_{n}$ for all $n \geq 1$. Then, $c_{n}^{(1)}=y_{n}$. By Lemma 2.11, we obtain

$$
\frac{1}{2 r_{n}} d^{2}\left(c_{n}^{(i)}, p\right)-\frac{1}{2 r_{n}} d^{2}\left(c_{n}^{(i+1)}, p\right)+\frac{1}{2 r_{n}} d^{2}\left(c_{n}^{(i+1)}, c_{n}^{(i)}\right)+h\left(c_{n}^{(i)}\right) \leq h(p) .
$$

Since $h(p) \leq h\left(c_{n}^{(i)}\right)$, we obtain

$$
d^{2}\left(c_{n}^{(i)}, c_{n}^{(i+1)}\right) \leq d^{2}\left(c_{n}^{(i+1)}, p\right)-d^{2}\left(c_{n}^{(i)}, p\right) .
$$


Now, taking the sum from $i=1$ to $i=N$ in (3.18), from (3.17) we obtain that

$$
\begin{aligned}
\sum_{i=1}^{N} d^{2}\left(c_{n}^{(i)}, c_{n}^{(i+1)}\right) & \leq d^{2}\left(c_{n}^{(N+1)}, p\right)-d^{2}\left(c_{n}^{(1)}, p\right) \\
& =d^{2}\left(v_{n}, p\right)-d^{2}\left(y_{n}, p\right) \\
& \leq d^{2}\left(y_{n}, v_{n}\right)+2 d\left(y_{n}, v_{n}\right) d\left(v_{n}, p\right) \rightarrow 0, \text { as } n \rightarrow \infty,
\end{aligned}
$$

which implies that

$$
\lim _{n \rightarrow \infty} d\left(c_{n}^{(i)}, c_{n}^{(i+1)}\right)=0, i=1,2, \cdots, N
$$

Thus, for each $i=1,2, \cdots, N$, we obtain by applying the triangle inequality that $\lim _{n \rightarrow 0} d\left(c_{n}^{(i)}, c_{n}^{(N+1)}\right)=0$. That is,

$$
\lim _{n \rightarrow \infty} d\left(c_{n}^{(i)}, v_{n}\right)=0, i=1,2, \cdots, N
$$

Since $r_{n} \geq r>0$ for all $n \geq 1$, from Lemma 2.5, Lemma 2.4, (3.19) and the nonexpansivity of $J_{r h_{i}}, i=1,2, \cdots, N$ we obtain that

$$
\begin{aligned}
d\left(c_{n}^{(i+1)}, J_{r h_{i}} c_{n}^{(i+1)}\right) & \leq d\left(c_{n}^{(i+1)}, J_{r_{n} h_{i}} c_{n}^{(i+1)}\right)+d\left(J_{r_{n} h_{i}} c_{n}^{(i+1)}, J_{r h_{i}} c_{n}^{(i+1)}\right) \\
& =d\left(c_{n}^{(i+1)}, c_{n}^{(i)}\right)+d\left(J_{r h_{i}}\left(\frac{r_{n}-r}{r_{n}} J_{r_{n} h_{i}} c_{n}^{(i+1)} \oplus \frac{r}{r_{n}} c^{(i+1)}\right), J_{r h_{i}} c_{n}^{(i+1)}\right) \\
& \leq d\left(c_{n}^{(i+1)}, c_{n}^{(i)}\right)+d\left(\frac{r_{n}-r}{r_{n}} J_{r_{n} h_{i}} c_{n}^{(i+1)} \oplus \frac{r}{r_{n}} c_{n}^{(i+1)}, c_{n}^{(i+1)}\right) \\
& \leq\left(2-\frac{r}{r_{n}}\right) d\left(c_{n}^{(i+1)}, c_{n}^{(i)}\right) \rightarrow 0, \text { as } n \rightarrow \infty, i=1,2, \cdots, N .
\end{aligned}
$$

By (3.19), (3.20) and (3.21), we obtain that

$$
\begin{aligned}
d\left(J_{r h_{i}} v_{n}, v_{n}\right) & \leq d\left(J_{r h_{i}} v_{n}, J_{r h_{i}} c_{n}^{(i+1)}\right)+d\left(J_{r h_{i}} c_{n}^{(i+1)}, c_{n}^{(i+1)}\right)+d\left(c_{n}^{(i+1)}, c_{n}^{(i)}\right)+d\left(c_{n}^{(i)}, v_{n}\right) \\
& \leq d\left(v_{n}, c_{n}^{(i)}\right)+d\left(c_{n}^{(i)}, c_{n}^{(i+1)}\right)+d\left(J_{r h_{i}} c_{n}^{(i+1)}, c_{n}^{(i+1)}\right)+d\left(c_{n}^{(i+1)}, c_{n}^{(i)}\right)+d\left(c_{n}^{(i)}, v_{n}\right) \\
& =2 d\left(v_{n}, c_{n}^{(i)}\right)+2 d\left(c_{n}^{(i)}, c_{n}^{(i+1)}\right)+d\left(J_{r h_{i}} c_{n}^{(i+1)}, c_{n}^{(i+1)}\right) \rightarrow 0, \text { as } n \rightarrow \infty .
\end{aligned}
$$

That is,

$$
\lim _{n \rightarrow \infty} d\left(J_{r h_{i}} v_{n}, v_{n}\right)=0, i=1,2, \cdots, N \text {. }
$$

Let $a_{n}=\beta_{n}^{(0)} v_{n} \oplus \beta_{n}^{(1)} y_{n} \oplus \beta_{n}^{(2)} y_{n} \cdots \oplus \beta_{n}^{(N)} y_{n}$. Then,

$$
\begin{aligned}
d\left(a_{n}, x_{n}\right) & =\beta_{n}^{(0)} d\left(v_{n}, x_{n}\right)+\sum_{i=1}^{N} \beta_{n}^{(i)} d\left(y_{n}, x_{n}\right) \\
& \leq \beta_{n}^{(0)} d\left(v_{n}, x_{n}\right)+\sum_{i=1}^{N} \beta_{n}^{(i)} d\left(y_{n}, v_{n}\right)+\sum_{i=1}^{N} \beta_{n}^{(i)} d\left(v_{n}, x_{n}\right),
\end{aligned}
$$

which implies from (3.14) and (3.17) that

$$
\lim _{n \rightarrow \infty} d\left(a_{n}, x_{n}\right)=0 .
$$

We know that $P_{D}$ is firmly nonexpansive. Thus, from (3.10), (3.11) and (3.15) we obtain that

$$
\begin{aligned}
d^{2}\left(z_{n}, a_{n}\right) & \leq d^{2}\left(a_{n}, p\right)-d^{2}\left(z_{n}, p\right) \\
& \leq d^{2}\left(v_{n}, p\right)-d^{2}\left(z_{n}, p\right) \\
& \leq d^{2}\left(v_{n}, p\right)-d^{2}\left(w_{n}, p\right) \\
& \leq d^{2}\left(v_{n}, w_{n}\right)+2 d\left(v_{n}, w_{n}\right) d\left(w_{n}, p\right) \rightarrow 0, \text { as } n \rightarrow \infty .
\end{aligned}
$$


From (3.23) and (3.24), we obtain that

$$
\lim _{n \rightarrow \infty} d\left(z_{n}, x_{n}\right)=0 .
$$

Using a similar method as in [50], [51] and [52], and the fact that $\left\{x_{n}\right\}$ is bounded, it follows from Lemma 2.8 that there exists a subsequence $\left\{x_{n_{k}}\right\}$ of $\left\{x_{n}\right\}$, such that $\Delta-\lim _{k \rightarrow \infty} x_{n_{k}}=z$. It follows from (3.25) that there exists a subsequence $\left\{z_{n_{k}}\right\}$ of $\left\{z_{n}\right\}$, such that $\Delta-\lim _{k \rightarrow \infty} z_{n_{k}}=z$. By a similar argument, we have that $\Delta-$ $\lim _{k \rightarrow \infty} v_{n_{k}}=z$. Since $T_{i_{\lambda}}$ is $\Delta$-demiclosed for each $i=1,2, \cdots, N$, it follows from (3.16) and Lemma 3.5 that $z \in \cap_{i=1}^{N} F\left(T_{i_{\lambda}}\right)=\cap_{i=1}^{N} F\left(T_{i}\right)$. Also, since $J_{r h_{i}}$ is nonexpansive, for each $i=1,2, \cdots, N$, we obtain from (3.22) and Lemma 2.10 that $z \in \cap_{i=1}^{N} F\left(U_{r h_{i}}\right)=\left(\cap_{i=1}^{N} \operatorname{argmin}_{y \in X} h_{i}(y)\right)$. Hence, $z \in \Gamma$.

Furthermore, for an arbitrary $u \in X$, by Lemma 2.9 we have that

$$
\limsup _{n \rightarrow \infty}\left\langle\overrightarrow{z u}, \overrightarrow{z x_{n}}\right\rangle \leq 0 \text {, }
$$

which implies by condition $\mathrm{C} 1$ that

$$
\limsup _{n \rightarrow \infty}\left(t_{n} d^{2}(z, u)+2\left(1-t_{n}\right)\left\langle\overrightarrow{z u}, \overrightarrow{z x_{n}}\right\rangle\right) \leq 0 .
$$

We now show that $\left\{x_{n}\right\}$ converges strongly to $z$. By (3.12) and Lemma 2.5, we obtain

$$
\begin{aligned}
d^{2}\left(x_{n+1}, z\right) & \leq d^{2}\left(v_{n}, z\right) \\
& \leq\left(1-t_{n}\right)^{2} d^{2}\left(z, x_{n}\right)+t_{n}^{2} d^{2}(z, u)+2 t_{n}\left(1-t_{n}\right)\left\langle\overrightarrow{z u}, \overrightarrow{z x_{n}}\right\rangle \\
& \leq\left(1-t_{n}\right) d^{2}\left(z, x_{n}\right)+t_{n}\left(t_{n} d^{2}(z, u)+2\left(1-t_{n}\right)\left\langle\overrightarrow{z u}, \overrightarrow{z x_{n}}\right\rangle\right) .
\end{aligned}
$$

Hence, by (3.27) and Lemma 2.12, we conclude that $\left\{x_{n}\right\}$ converges strongly to $z$.

Case 2: Suppose that $\left\{d^{2}\left(x_{n}, p\right)\right\}$ is not monotonically non-increasing. Then, there exists a subsequence $\left\{d^{2}\left(p, x_{n_{i}}\right)\right\}$ of $\left\{d^{2}\left(p, x_{n}\right)\right\}$, such that $d^{2}\left(p, x_{n_{i}}\right)<d^{2}\left(p, x_{n_{i}+1}\right)$ for all $i \in \mathbb{N}$. Thus, by Lemma 2.13 , there exists a non-decreasing sequence $\left\{m_{k}\right\} \subset \mathbb{N}$, such that $m_{k} \rightarrow \infty$, and

$$
d^{2}\left(p, x_{m_{k}}\right) \leq d^{2}\left(p, x_{m_{k}+1}\right) \text { and } d^{2}\left(p, x_{k}\right) \leq d^{2}\left(p, x_{m_{k}+1}\right) \text { for all } k \in \mathbb{N} .
$$

Thus, by (3.12), (3.29) and Lemma 2.5, we obtain

$$
\begin{aligned}
0 & \leq \lim _{k \rightarrow \infty}\left(d^{2}\left(p, x_{m_{k}+1}\right)-d^{2}\left(p, x_{m_{k}}\right)\right) \\
& \leq \limsup _{n \rightarrow \infty}\left(d^{2}\left(p, x_{n+1}\right)-d^{2}\left(p, x_{n}\right)\right) \\
& \leq \limsup _{n \rightarrow \infty}\left(d^{2}\left(p, z_{n}\right)-d^{2}\left(p, x_{n}\right)\right) \\
& \leq \limsup _{n \rightarrow \infty}\left(\left(1-t_{n}\right) d^{2}\left(p, x_{n}\right)+t_{n} d^{2}(p, u)-d^{2}\left(p, x_{n}\right)\right) \\
& =\limsup _{n \rightarrow \infty}\left[t_{n}\left(d^{2}(p, u)-d^{2}\left(p, x_{n}\right)\right)\right]=0,
\end{aligned}
$$

which implies that

$$
\lim _{k \rightarrow \infty}\left(d^{2}\left(p, x_{m_{k}+1}\right)-d^{2}\left(p, x_{m_{k}}\right)\right)=0 .
$$

Following the arguments as in Case 1, we can show that

$$
\lim _{k \rightarrow \infty}\left(t_{m_{k}} d^{2}(z, u)+2\left(1-t_{m_{k}}\right)\left\langle\overrightarrow{z u}, \overrightarrow{z x_{m_{k}}}\right\rangle\right) \leq 0 .
$$

Also, by (3.28), we have

$$
d^{2}\left(z, x_{m_{k}+1}\right) \leq\left(1-t_{m_{k}}\right) d^{2}\left(z, x_{m_{k}}\right)+t_{m_{k}}\left(t_{m_{k}} d^{2}(z, u)+2\left(1-t_{m_{k}}\right)\left\langle\overrightarrow{z u}, \overrightarrow{z x_{m_{k}}}\right\rangle\right) .
$$


Since $d^{2}\left(z, x_{m_{k}}\right) \leq d^{2}\left(z, x_{m_{k}+1}\right)$, we obtain

$$
d^{2}\left(z, x_{m_{k}}\right) \leq\left(t_{m_{k}} d^{2}(z, u)+2\left(1-t_{m_{k}}\right)\left\langle\overrightarrow{z u}, \overrightarrow{z x_{m_{k}}}\right\rangle\right) .
$$

Thus, by (3.31), we get

$$
\lim _{k \rightarrow \infty} d^{2}\left(z, x_{m_{k}}\right)=0 .
$$

It then follows from (3.29), (3.30) and (3.32) that $\lim _{k \rightarrow \infty} d^{2}\left(z, x_{k}\right)=0$. Therefore, we conclude from both cases that $\left\{x_{n}\right\}$ converges to $z \in \Gamma$.

By setting $N=1$ in Theorem 3.6, we obtain the following result:

Corollary 3.7. Let $D$ be a nonempty closed and convex subset of a complete CAT(O) space $X$, and $h: X \rightarrow$ $(-\infty, \infty]$ be a proper, convex and lower semi-continuous function. Let $T: D \rightarrow D$ be a $k$-demimetric mapping with $k \in(-\infty, \lambda]$ and $\lambda \in(0,1)$. Suppose that $\Gamma=\left(\left(\operatorname{argmin}_{u \in X} h(u)\right) \cap F(T)\right)$ is nonempty and for arbitrary $x_{1}, u \in X$ the sequence $\left\{x_{n}\right\}$ is defined by

$$
\left\{\begin{array}{l}
v_{n}=\left(1-t_{n}\right) x_{n} \oplus t_{n} u, \\
y_{n}=J_{r_{n} h} v_{n}, \\
z_{n}=P_{D}\left(\beta_{n}^{(0)} v_{n} \oplus \beta_{n}^{(1)} y_{n}\right), \\
w_{n}=\gamma_{n}^{(0)} z_{n} \oplus \gamma_{n}^{(1)} T_{\lambda} z_{n}, \\
x_{n+1}=\alpha_{n} v_{n} \oplus\left(1-\alpha_{n}\right) w_{n} \text { for all } n \geq 1,
\end{array}\right.
$$

where $T_{\lambda}$ is as defined in Lemma 3.5, such that $T_{\lambda}$ is $\Delta$-demiclosed. Suppose that $\left\{t_{n}\right\},\left\{\alpha_{n}\right\},\left\{\beta_{n}\right\}$ and $\left\{\gamma_{n}\right\}$ are sequences in [0,1], such that the following conditions are satisfied:

$C 1: 0<a \leq \alpha_{n}, \beta_{n}^{(i)}, \gamma_{n}^{(i)} \leq b<1, \sum_{i=0}^{1} \beta_{n}^{(i)}=1$ and $\sum_{i=0}^{1} \gamma_{n}^{(i)}=1$ for all $n \geq 1$,

C2: $\lim _{n \rightarrow \infty} t_{n}=0, \sum_{n=1}^{\infty} t_{n}=\infty$,

C3: $\left\{r_{n}\right\}$ is a sequence of real numbers such that $r_{n} \geq r>0$.

Then, the sequence $\left\{x_{n}\right\}$ converges strongly to a point in $\Gamma$.

By setting $T_{i}$ to be a $k$-demicontractive mapping for each $i=1,2, \ldots, N$ in Theorem 3.6, we obtain the following result:

Corollary 3.8. Let $D$ be a nonempty closed and convex subset of a complete CAT(O) space $X$, and $h_{i}: X \rightarrow$ $(-\infty, \infty], i=1, \cdots, N$ be a finite family of proper convex and lower semi-continuous functions. Let $T_{i}: X \rightarrow X$, $i=1, \cdots, N$ be a finite family of $k_{i}$-demicontactive mappings with $k_{i} \in(-\infty, \lambda]$ and $\lambda \in(0,1)$. Suppose that $\Gamma=\left(\cap_{i=1}^{N} \operatorname{argmin}_{u \in X} h_{i}(u)\right) \cap\left(\cap_{i=1}^{N} F\left(T_{i}\right)\right)$ is nonempty and $\left\{x_{n}\right\}$ is a sequence generated for arbitrary $x_{1}, u \in X$ by

$$
\left\{\begin{array}{l}
v_{n}=\left(1-t_{n}\right) x_{n} \oplus t_{n} u, \\
y_{n}=J_{r_{n} h_{1}} \circ J_{r_{n} h_{2}} \circ \cdots \circ J_{r_{n} h_{N}} v_{n}, \\
z_{n}=P_{D}\left(\beta_{n}^{(0)} v_{n} \oplus \beta_{n}^{(1)} y_{n} \oplus \cdots \oplus \beta_{n}^{(N)} y_{n}\right), \\
w_{n}=\gamma_{n}^{(0)} z_{n} \oplus \gamma_{n}^{(1)} T_{1 \lambda} z_{n} \oplus \gamma_{n}^{(1)} T_{2 \lambda} z_{n} \cdots \oplus \gamma_{n}^{(N)} T_{N \lambda} z_{n}, \\
x_{n+1}=\alpha_{n} v_{n} \oplus\left(1-\alpha_{n}\right) w_{n} \text { for all } n \geq 1,
\end{array}\right.
$$

where $T_{i \lambda} x=\lambda x \oplus(1-\lambda) T_{i} x$, such that $T_{i \lambda}$ are $\Delta$-demiclosed for each $i=1,2, \ldots, N$. Suppose that $\left\{t_{n}\right\},\left\{\alpha_{n}\right\}$, $\left\{\beta_{n}^{(i)}\right\}$ and $\left\{\gamma_{n}^{(i)}\right\}$ are sequences in [0,1], such that the following conditions are satisfied:

$C 1: 0<a \leq \alpha_{n}, \beta_{n}^{(i)}, \gamma_{n}^{(i)} \leq b<1, \sum_{i=0}^{N} \beta_{n}^{(i)}=1$ and $\sum_{i=0}^{N} \gamma_{n}^{(i)}=1$ for all $n \geq 1$,

$C 2: \lim _{n \rightarrow \infty} t_{n}=0, \sum_{n=1}^{\infty} t_{n}=\infty$,

C3: $\left\{r_{n}\right\}$ is a sequence of real numbers such that $r_{n} \geq r>0$ for all $n \geq 1$.

Then, the sequence $\left\{x_{n}\right\}$ converges strongly to a point in $\Gamma$. 


\section{Numerical example}

In this section, we give a numerical example to illustrate Theorem 3.6.

Let $X=\mathbb{R}$, endowed with the usual metric and $D=[0,1]$. Then,

$$
P_{D}(x)=\left\{\begin{array}{l}
0, \text { if } x<0, \\
x, \text { if } x \in D, \\
1, \text { if } x>1
\end{array}\right.
$$

is a metric projection onto $D$. For $N=2$, define $T_{i}: D \rightarrow D$, by $T_{i} x=x-x^{i}, i=1,2$. Then, $T$ is (-1)-demimetric (see Example 3.3). Now, define $h_{i}: \mathbb{R} \rightarrow(-\infty, \infty]$ by $h_{i}(x)=\frac{1}{2}\left|B_{i}(x)-b_{i}\right|^{2}$, where $B_{i}(x)=2 i x$ and $b_{i}=0$, $i=1$, 2. Since $B_{i}$ is continuous and linear for each $i=1$, 2, then we have that $h_{i}$ is proper, convex and lower semicontinuous mapping. Let $r_{n}=1$ for all $n \geq 1$, then

$$
\begin{aligned}
J_{1 h_{i}}(x)=\operatorname{Proxh}_{i} x & =\arg \min _{y \in D}\left(h_{i}(y)+\frac{1}{2}|y-x|^{2}\right) \\
& =\left(I+B_{i}^{T} B_{i}\right)^{-1}\left(x+B_{i}^{T} b_{i}\right) .
\end{aligned}
$$

Take $t_{n}=\frac{1}{2 n+1}, \beta_{n}^{(0)}=\frac{n}{4 n+1}, \beta_{n}^{(1)}=\frac{n+1}{4 n+1}, \beta_{n}^{(2)}=\frac{2 n}{4 n+1}, \gamma_{n}^{(0)}=\frac{3 n}{5 n+7}, \gamma_{n}^{(1)}=\frac{n+7}{5 n+7}, \gamma_{n}^{(2)}=\frac{n}{5 n+7}$ and $\alpha_{n}=\frac{4 n}{6 n+1}$, then conditions $\mathrm{C} 1$ and $\mathrm{C} 2$ of Theorem 3.6 are satisfied. Therefore, for $x_{1}, u \in \mathbb{R}$, after applying our algorithm (3.9) becomes

$$
\left\{\begin{array}{l}
v_{n}=\left(1-t_{n}\right) x_{n}+t_{n} u, \\
y_{n}=J_{1}^{(1)}\left(J_{1}^{(2)}\left(v_{n}\right)\right), \\
z_{n}=P_{D}\left(\beta_{n}^{(0)} v_{n}+\beta_{n}^{(1)} y_{n}+\beta_{n}^{(2)} y_{n}\right), \\
w_{n}=\gamma_{n}^{(0)} z_{n}+\gamma_{n}^{(1)} T_{1 \lambda} z_{n}+\gamma_{n}^{(2)} T_{2 \lambda} z_{n}, \\
x_{n+1}=\alpha_{n} v_{n}+\left(1-\alpha_{n}\right) w_{n} \text { for all } n \geq 1 .
\end{array}\right.
$$

Case 1: Take $x_{1}=0.5$ and $u=0.5$.

Case 2: Take $x_{1}=0.5$ and $u=1$.

Case 3: Take $x_{1}=1$ and $u=0.5$.

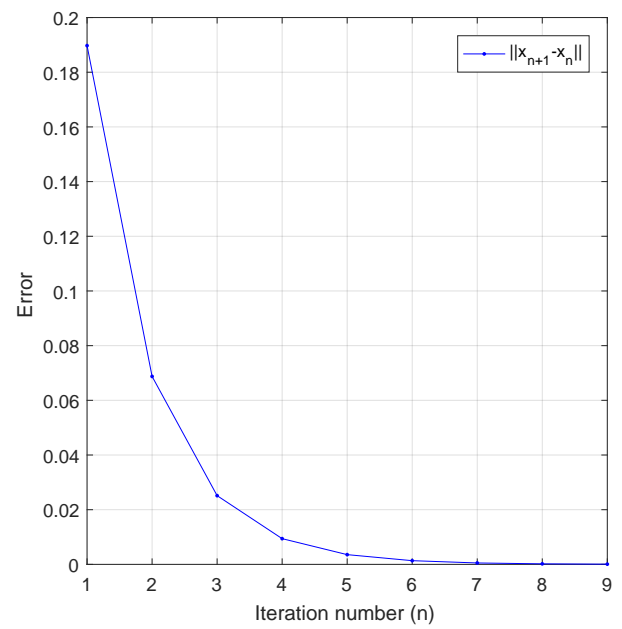

Figure 1: Errors vs number of iterations for Case 1. 


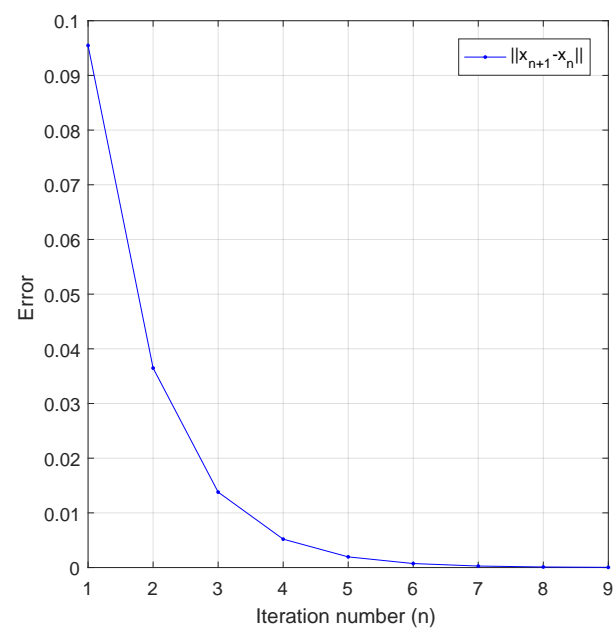

Figure 2: Errors vs number of iterations for Case 2.

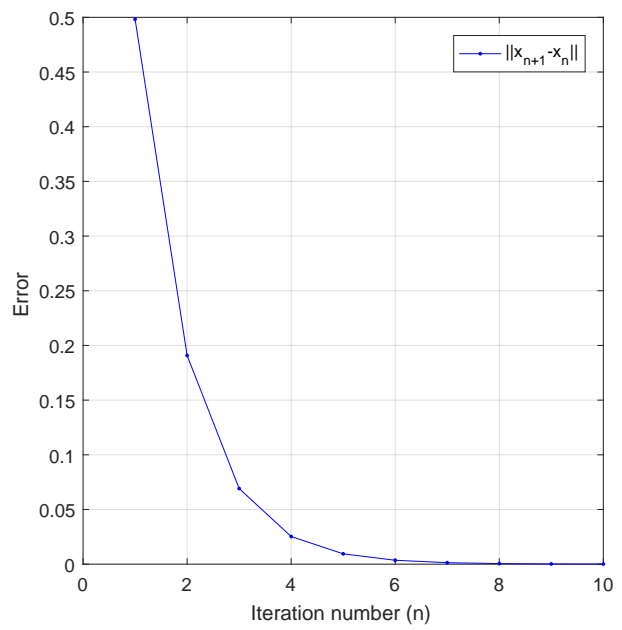

Figure 3: Errors vs number of iterations for Case 3.

\section{Declaration}

The authors declare that they have no competing interests.

\section{References}

[1] Izuchukwu C., Okeke C. C., Mewomo 0. T., Systems of variational inequalities and multiple-set split equality fixed point problems for countable families of multi-valued type-one demicontractive-type mappings, Ukrainian Math. J. (Accepted, to appear, 2020)

[2] Takahashi W., The split common fixed point problem and the shrinking projection method in Banach spaces, J. Convex Anal., 2017, 24(3), 1015-1028

[3] Takahashi W., Strong convergence theorem for a finite family of demimetric mappings with variational inequality problems in a Hilbert space, Japan J. Indust. Appl. Math., 2017, 34(1), 41-57

[4] Takahashi W., Wen C. F., Yao J. C., The shrinking projection method for a finite of family demimetric mappings with variational inequality problems in a Hilbert space, Fixed Point Theory, 2017, 19(1), 109-116 
[5] Komiya H., Takahashi W., Strong convergence theorem for an infinite family of demimetric mappings in a Hilbert space, J. Convex Anal., 2017, 24(4), 1357-1373

[6] Mewomo O.T., Ogbuisi F.U., Convergence analysis of iterative method for multiple set split feasibility problems in certain Banach spaces, Quaest. Math., 2018, 41(1), 129-148

[7] Ogbuisi F.U., Mewomo O.T., Iterative solution of split variational inclusion problem in real Banach space, Afr. Mat., 2017, 28(1-2), 295-309

[8] Ogbuisi F.U., Mewomo O.T., Convergence analysis of common solution of certain nonlinear problems, Fixed Point Theory, 2018, 19(1), 335-358

[9] Ogbuisi F.U., Mewomo O.T., On split generalized mixed equilibrium problems and fixed point problems with no prior knowledge of operator norm, J. Fixed Point Theory Appl., 2017, 19(3), 2109-2128

[10] Okeke C.C., Mewomo O.T., On split equilibrim problem, variational inequality problem and fixed point problem for multivalued mappings, Ann. Acad. Rom. Sci. Ser. Math. Appl., 2017, 9(2), 255-280

[11] Shehu Y., Mewomo O.T., Further investigation into split common fixed point problem for demicontractive operators, Acta Math, Sin. (Engl. Ser.), 2016, 32(11), 1357-1376

[12] Shehu Y., Ogbuisi F.U., Mewomo O.T., Further investigation into approximation of a common solution of fixed point problems and split feasibility problems, Acta. Math. Sci. Ser. B, Engl. Ed., 2016, 36(3), 913-930

[13] Kirk W. A., Geodesic geometry and fixed point theory, In: Seminar of Mathematical Analysis, (Univ. Sevilla Secr. Publ., Seville, 2003), 195-225

[14] Dhompongsa S., Panyanak B., On $\Delta$-convergence theorems in CAT(0) spaces, Comp. Math. Appl., 2008, 56(10), 2572-2579

[15] Khan S. H., Abbas M., Strong $\Delta$-convergence of some iterative schemes in CAT(0) spaces, Comp. Math. Appl., 2011, 61(1), 109-116

[16] Chang S. S., Wang L., Joseph Lee H. W., Chan C. K., Yang L., Demiclosed principle and $\Delta$-convergence theorems for total asymptotically nonexpansive mappings in CAT(0) spaces, Appl. Math. Comp., 2012, 219(5) 2611-2617

[17] Berg I. D., Nikolaev I. G., Quasilinearization and curvature of Alexandrov spaces, Geom. Dedicata, 2008, 133(1), 195-218

[18] Liu X., Chang S. S., Convergence theorems on total asymptotically demicontractive and hemicontractive mappings in CAT(0) spaces, J. Inequal. Appl., 2014, 436, 109-116

[19] Jost J., Convex functionals and generalized harmonic maps into spaces of nonpositive curvature, Comment. Math. Helv., $1995,70,659-673$

[20] Martinet B., Regularisation d' inequations varaiationnelles par approximations successives, Rev. Fr. Inform. Rec. Oper., 1970, 4(3), 154-158

[21] Rockafellar R. T., Monotone operators and the proximal point algorithm, SIAM J. Control Optim., 1976, 14, 877-898

[22] Kamimura S., Takahashi W., Approximating solutions of maximal monotone operators in Hilbert spaces, J. Approx. Theory, 2000, 106(2), 226-240

[23] Boikanyo O. A., Morosanu G., A proximal point algorithm converging strongly for general errors, Optim. Lett., 2010, 4(4), 635-641

[24] Marino G., Xu H. K., Convergence of generalized proximal point algorithm, Commun. Pure Appl., 2004, 3(4), 791-808

[25] Xu H. K., A regularization for the proximal point algorithm, J. Glob. Optim., 2006, 36(1), 115-125

[26] Yao Y., Noor M. A., On convergence criteria of generalized proximal point algorithm, J. Comput. Appl. Math., 2008, 217(1), 46-55

[27] Brézis H., Lions P. L., Produits infinis de resolvantes, Israel J. Math., 1978, 29(4), 329-345

[28] Saejung S., Yotkaew P., Approximation of zeros of inverse strongly monotone operators in Banach spaces, Nonlinear Anal., 2012, 75(2), 742-750

[29] Bačák M., The proximal point algorithm in metric spaces, Israel J. Math., 2013, 194(2), 689-701

[30] Cholamjiak P., Abdou A. N., Cho Y. Y., Proximal point algorithms involving fixed points of nonexpansive mappings in CAT(0) spaces, Fixed Point Theory Appl., 2015, 227, DOI 10.1186/s13663-015-0465-4

[31] Lerkchaiyaphum K., Phuengrattana W., Iterative approaches to solving convex minimization problems and fixed point problem in complete CAT(0) Spaces, Numer. Algorithms, 2018, 77(3), 727-740

[32] Bridson M. R., Haefliger A., Metric Spaces of Non-Positive Curvature, Fundamental Principle of Mathematical Sciences, Springer-Verlag, Berlin, Germany, 1999, 319

[33] Brown K. S., Buildings, Springer, New York, NY, 1989

[34] Jost J., Nonpositive Curvature: Geometric and Analytic Aspects, Lectures Math. ETH Zurich, Birkhauser, Basel, 1997

[35] Dhompongsa S., Kirk W. A., Sims B., Fixed points of uniformly Lipschitzian mappings, Nonlinear Anal., 2006, 65(4), 762-772

[36] Kirk. W. A, Panyanak B., A concept of convergence in geodesic spaces, Nonlinear Anal., 2008, 68(12), 3689-3696

[37] Khatibzadeh H., Ranjbar S., Monotone operators and the proximal point algorithm in complete CAT(0) metric spaces, J. Aust. Math Soc., 2017, 103(1), 70-90

[38] Ariza-Ruiz D., Leustean L., G. López-Acedo G., Firmly nonexpansive mappings in classes of geodesic spaces, Trans. Amer. Math. Soc., 2014, 366(8), 4299-4322

[39] Ariza-Ruiz D., López-Acedo G., Nicolae A., The asymptotic behavior of the composition of firmly nonexpansive mappings, J. Optim. Theory Appl., 2015, 167(2), 409-429 
[40] Dehghan H., Rooin J., Metric projection and convergence theorems for nonexpansive mapping in Hadamard spaces, arXiv:1410.1137VI [math.FA]

[41] Wangkeeree R., Preechasilp P., Viscosity approximation methods for nonexpansive mappings in CAT(0) Spaces, J. Inequal. Appl., 2013, 93

[42] Chidume C. E., Bello A. U., Ndambomve P., Strong and $\Delta$-convergence theorems for common fixed points of a finite family of multivalued demicontractive mappings in CAT(0) spaces, Abstr. Appl. Anal., 2014, Article ID 805168

[43] Leuştean L., Nonexpansive iterations uniformly cover W-hyperbolic spaces, Nonlinear Analysis and Optimization 1: Nonlinear Analysis, Contemporary Math. Am. Math. Soc., Providence, 2010, 513, 193-209

[44] Kakavandi B. A., Amini M., Duality and subdifferential for convex functions on complete CAT(0) metric spaces, Nonlinear Anal., 2010, 73(10), 3450-3455

[45] Dhompongsa S., Kirk W. A., Panyanak B., Nonexpansive set-valued mappings in metric and Banach spaces, J. Nonlinear Convex Anal., 2007, 8(1), 35-45

[46] Laowang W., Panyanak B., Strong and $\Delta$-convergence theorems for multivalued mappings in CAT(0) spaces, J. Inequal. Appl., 2009, Art. ID 730132

[47] Xu H. K., Iterative algorithms for nonlinear operators, J. Lond. Math. Soc., 2002, 66(1), 240-256

[48] Maingé P. E., Strong convergence of projected subgradient methods for nonsmooth and nonstrictly convex minimization, Set-Valued Anal., 2008, 16(7), 899-912

[49] Browder F. E., Petryshyn W. V., Construction of fixed points of nonlinear mappings in Hilbert spaces, J. Math. Anal. Appl., $1967,20,197-228$

[50] Browder F. E., Convergence of approximants to fixed points of nonexpansive nonlinear mappings in Banach spaces, Arch. Rational Mech. Anal., 1967, 24, 82-90

[51] Ugwunnadi G. C., Khan A. R., Abbas M., A hybrid proximal point algorithm for finding minimizers and fixed points in CAT(0) spaces, J. Fixed Point Theory Appl., 2018, 20(2), DOI 10.1007/s11784-018-0555-0

[52] Ugwunnadi G. C., Izuchukwu C., Mewomo O. T., On nonspreading-type mappings in Hadamard spaces, Bol. Soc. Paran. Mat., $2018,22,1-23$ 